\title{
Digital Image Steganography Using Eight-Directional PVD against RS Analysis and PDH Analysis
}

\author{
Gandharba Swain (D) \\ Department of Computer Science and Engineering, Koneru Lakshmaiah Education Foundation, Vaddeswaram, \\ Andhra Pradesh 522502, India \\ Correspondence should be addressed to Gandharba Swain; gswain1234@gmail.com
}

Received 16 June 2017; Revised 19 August 2017; Accepted 7 September 2017; Published 26 September 2018

Academic Editor: Martin Reisslein

Copyright (C) 2018 Gandharba Swain. This is an open access article distributed under the Creative Commons Attribution License, which permits unrestricted use, distribution, and reproduction in any medium, provided the original work is properly cited.

\begin{abstract}
The least significant bit (LSB) substitution techniques are detected by RS analysis and the traditional pixel value differencing (PVD) approaches are detected by pixel difference histogram (PDH) analysis. The PVD steganography can escape from PDH analysis by using the edges in multiple directions. This paper proposes a steganography technique by exploiting the edges in eight directions and also using LSB substitution to resist from both RS analysis and PDH analysis. For every $3 \times 3$ pixel block the central pixel is embedded with 3 or 4 bits of data by modified LSB substitution technique. Then this new value of the central pixel is utilized to calculate eight difference values with eight neighboring pixels. These eight difference values are used to hide the data. There are two types with regard to two different range tables. Type 1 uses 3 bit modified LSB substitution and range table 1 . Type 2 uses 4 bit modified LSB substitution and range table 2. Type 1 and type 2 are also known as variant 1 and variant 2, respectively. Type 1 possesses higher PSNR and type 2 possesses higher hiding capacity.
\end{abstract}

\section{Introduction}

The LSB substitution is one of the simplest and wellknown approaches for data hiding. This simplest technique is detected by RS analysis. Wu and Tsai [1] exposed the fact that the edge regions in an image can conceal more amounts of data as compared to the smooth regions. Based on this principle they proposed pixel value differencing (PVD) steganography. The image should be partitioned into different blocks, each of size $1 \times 2$ pixels. For a block the difference value between the two pixels is computed and changed to a new value by adding data to it. The PVD technique with block size of $2 \times 2$ has been proposed to improve the embedding capacity $[2,3]$. In blocks of size $2 \times 2$, edges in three directions are considered. Chang and Tseng [4] considered the values of 2, 3, and 4 neighboring pixels, to calculate the pixel value differences. But they did not address the fall in error problem (FIEP). Yang et al. [5] calculated varieties of pixel value differences in 4-pixel blocks for data hiding. Hong et al. [6] used diamond encoding with pixel value differencing to achieve better PSNR. LSB substitution techniques offer higher embedding capacity, but
PVD techniques offer higher imperceptibility. Thus PVD and LSB techniques have been combined to obtain larger hiding capacity and better imperceptibility [7, 8]. Chen [9] proposed a PVD steganography using two reference tables to randomize the data embedding. Khodaei and Faez [10] proposed a hybrid approach by combining LSB substitution and PVD in $1 \times 3$ pixel block. It was further extended to $2 \times 2$ size block in [11] to achieve better performance. Based on pixel value differences adaptive LSB substitution has been performed in $[12,13]$.

The traditional PVD steganography techniques follow a static range table. Due to this some undesired steps are introduced in pixel difference histograms of the stego images. This step effects can be avoided by applying two tricks, (i) exploiting the edges in multiple directions and (ii) using adaptive range table. Luo et al. [14] also proposed an adaptive PVD steganography with three-pixel blocks, which does not suffer with the step effects. Swain [15] proposed two adaptive PVD steganography techniques using vertical, horizontal, and diagonal edges, which do not suffer from step effects. The first technique uses pixel blocks of size $2 \times 2$ and the second technique uses pixel blocks of size $3 \times 3$. In general, adaptive 
TABLE 1: Range table 1 (for type 1).

\begin{tabular}{lcccccc}
\hline Range & $\mathrm{R}_{1}=[0,7]$ & $\mathrm{R}_{2}=[8,15]$ & $\mathrm{R}_{3}=[16,31]$ & $\mathrm{R}_{4}=[32,63]$ & $\mathrm{R}_{5}=[64,127]$ & $\mathrm{R}_{6}=[128,255]$ \\
\hline capacity & 3 & 3 & 3 & 3 & 4 & 4 \\
\hline
\end{tabular}

TABle 2: Range Table 2 ( for type 2).

\begin{tabular}{lcccccc}
\hline Range & $\mathrm{R}_{1}=[0,7]$ & $\mathrm{R}_{2}=[8,15]$ & $\mathrm{R}_{3}=[16,31]$ & $\mathrm{R}_{4}=[32,63]$ & $\mathrm{R}_{5}=[64,127]$ & 6 \\
\hline capacity & 3 & 3 & 4 & 5 & $\mathrm{R}_{6}=[128,255]$ \\
\hline
\end{tabular}

\begin{tabular}{|l|l|l|}
\hline$P_{1}$ & $P_{2}$ & $P_{3}$ \\
\hline$P_{4}$ & $P_{c}$ & $P_{5}$ \\
\hline$P_{6}$ & $P_{7}$ & $P_{8}$ \\
\hline
\end{tabular}

(a)

\begin{tabular}{|l|l|l|}
\hline$P_{1}^{\prime}$ & $P_{2}^{\prime}$ & $P_{3}^{\prime}$ \\
\hline$P_{4}^{\prime}$ & $P_{c}^{\prime}$ & $P_{5}^{\prime}$ \\
\hline$P_{6}^{\prime}$ & $P_{7}^{\prime}$ & $P_{8}^{\prime}$ \\
\hline
\end{tabular}

(b)

FIGURE 1: (a) Original block; (b) stego block.

image steganography schemes possess lower hiding capacity. The edges can be predicted by some prediction functions and hiding capacity depends upon this prediction. If we hide in smooth regions distortion will be more. Based on the level of complexity of the edge regions, adaptive embedding can be applied [16]. In this way capacity can be increased and chance of detection can be decreased. Balasubramanian et al. [17] published PVD schemes with $3 \times 3$ size pixel blocks, to achieve higher hiding capacity. To prevent the detection from pixel difference histogram (PDH) analysis, multidirectional edges have been exploited in [18]. Darabkh et al. [19] also proposed PVD steganography using eight-directional PVD which is an extension from Wu and Tsai's original PVD. A PVD steganography technique which is an extension of Wu and Tsai's PVD approach should be verified by $\mathrm{PDH}$ analysis. Gulve and Joshi [20] used PVD with LSB in six-pixel blocks to achieve higher embedding capacity. In one of the six pixels LSB substitution was applied. Then five differences were calculated and based on these differences PVD approach was applied.

Zhang and Wang [21] proposed exploiting modification direction (EMD) steganography. The main goal in it is that a group of secret bits is converted to a digit in $(2 n+1)$-ary notational system, where $\mathrm{n}$ is the size of pixel block. This secret digit could be hidden in the pixel block by adding \pm 1 to only one pixel. In this technique the hiding capacity is not good. Kim [22] advanced the EMD technique using basis vector and $\left(2^{\mathrm{n}+\mathrm{x}}-1\right)$-ary notational system, where $\mathrm{n}$ and $x$ are user defined values. Shen and Huang [23] made the hiding capacity of a block adaptive using PVD with EMD to achieve higher hiding capacity and better PSNR. Nguyen et al. [24] used multiple bit planes and pixel block complexity measure to perform adaptive embedding. In this method more number of bits is hidden in high textured regions as compared to low textured regions. In [25] the steganography algorithm uses a public key and a private key to generate pseudo random numbers that identify the embedding locations.

This paper proposes a combination of modified LSB substitution and eight-directional PVD in $3 \times 3$ pixel blocks. It is judiciously designed in such a manner that it can neither be detected by RS analysis nor be detected by PDH analysis. Furthermore Wu and Tsai's PVD principle is not used.

\section{Proposed Eight-Directional PVD Technique}

The embedding algorithm operates on $3 \times 3$ pixel blocks. The blocks are formed in a nonoverlapping manner. Let us denote a typical block as in Figure 1(a). The central pixel is $\mathrm{P}_{c}$ and its surrounding pixels are $\mathrm{P}_{1}, \mathrm{P}_{2}, \mathrm{P}_{3}, \mathrm{P}_{4}, \mathrm{P}_{5}, \mathrm{P}_{6}, \mathrm{P}_{7}$, and $\mathrm{P}_{8}$. In central pixel $t$ bit LSB substitution is performed. For type 1 , the $t$ value is 3 and range table is Table 1 . For type 2 , the $t$ value is 4 and the range table is Table 2 .

After performing $t$ bit LSB substitution in $\mathrm{P}_{c}$, the stego value is $\mathrm{P}_{c}^{\prime}$. Suppose the integer (decimal) value of $t$ LSB bits in $\mathrm{P}_{\mathrm{c}}$ is $\mathrm{dec}_{\mathrm{old}}$ and the integer (decimal) value of $\mathrm{t}$ LSB bits in $\mathrm{P}_{\mathrm{c}}^{\prime}$ is $\mathrm{dec}_{\text {new }}$. Now find the deviation, dev $=\mathrm{dec}_{\mathrm{old}}-\mathrm{dec}_{\text {new }}$. Furthermore calculate a modified value of $\mathrm{P}_{\mathrm{c}}^{\prime}$ as in

$$
\begin{aligned}
& \mathrm{P}_{\mathrm{c}}^{\prime} \\
& = \begin{cases}\mathrm{P}_{\mathrm{c}}^{\prime}+2^{\mathrm{t}}, & \text { if } \mathrm{dev}>2^{\mathrm{t}-1} \text { and } 0 \leq \mathrm{P}_{\mathrm{c}}^{\prime}+2^{\mathrm{t}} \leq 255 \\
\mathrm{P}_{\mathrm{c}}^{\prime}-2^{\mathrm{t}}, & \text { if } \operatorname{dev}<-2^{\mathrm{t}-1} \text { and } 0 \leq \mathrm{P}_{\mathrm{c}}^{\prime}-2^{\mathrm{t}} \leq 255 \\
\mathrm{P}_{\mathrm{c}}^{\prime}, & \text { otherwise }\end{cases}
\end{aligned}
$$

Using this modified value $\mathrm{P}_{c}^{\prime}$, calculate eight difference values $\mathrm{d}_{\mathrm{i}}$, for $\mathrm{i}=1$ to 8 as in

$$
\mathrm{d}_{\mathrm{i}}=\left|\mathrm{P}_{\mathrm{c}}^{\prime}-\mathrm{P}_{\mathrm{i}}\right|
$$


The difference value $d_{1}$ belongs to one of the six ranges. Suppose the lower bound is denoted as $\mathrm{L}_{1}$ and hiding capacity as $t_{1}$ for the range of $\mathrm{d}_{1}$. Similarly $\mathrm{L}_{2}, \mathrm{~L}_{3}, \mathrm{~L}_{4}, \mathrm{~L}_{5}, \mathrm{~L}_{6}, \mathrm{~L}_{7}$, and $\mathrm{L}_{8}$ are the lower bounds and $t_{2}, t_{3}, t_{4}, t_{5}, t_{6}, t_{7}$, and $t_{8}$ are the hiding capacities of the ranges of $\mathrm{d}_{2}, \mathrm{~d}_{3}, \mathrm{~d}_{4}, \mathrm{~d}_{5}, \mathrm{~d}_{6}, \mathrm{~d}_{7}$, and $\mathrm{d}_{8}$, respectively.

Now take $t_{1}, t_{2}, t_{3}, t_{4}, t_{5}, t_{6}, t_{7}$, and $t_{8}$ bits of data separately and convert to their decimal values $S_{1}, S_{2}, S_{3}, S_{4}, S_{5}, S_{6}, S_{7}$, and $\mathrm{S}_{8}$, respectively.

Now for $\mathrm{i}=1$ to 8 , calculate new difference values $\mathrm{d}_{\mathrm{i}}^{\prime}$ using

$$
\mathrm{d}_{\mathrm{i}}^{\prime}=\mathrm{L}_{\mathrm{i}}+\mathrm{S}_{\mathrm{i}}
$$

For $\mathrm{i}=1$ to 8 a pair of new values for each $\mathrm{P}_{\mathrm{i}}$ is calculated as in

$$
\begin{aligned}
& \mathrm{P}_{\mathrm{i}}^{\prime \prime}=\mathrm{P}_{\mathrm{c}}^{\prime}-\mathrm{d}_{\mathrm{i}}^{\prime} \\
& \mathrm{P}_{\mathrm{i}}^{\prime \prime \prime}=\mathrm{P}_{\mathrm{c}}^{\prime}+\mathrm{d}_{\mathrm{i}}^{\prime}
\end{aligned}
$$

Now out of two new values $\mathrm{P}_{\mathrm{i}}^{\prime \prime}$ and $\mathrm{P}_{\mathrm{i}}^{\prime \prime \prime}$, one value is chosen for $\mathrm{P}_{\mathrm{i}}^{\prime}$ using

$$
\begin{aligned}
& \mathrm{P}_{\mathrm{i}}^{\prime} \\
& = \begin{cases}\mathrm{P}_{\mathrm{i}}^{\prime \prime}, & \text { if }\left|\mathrm{P}_{\mathrm{i}}-\mathrm{P}_{\mathrm{i}}^{\prime \prime}\right|<\left|\mathrm{P}_{\mathrm{i}}-\mathrm{P}_{\mathrm{i}}^{\prime \prime \prime}\right| \text { and } 0 \leq \mathrm{P}_{\mathrm{i}}^{\prime \prime} \leq 255 \\
\mathrm{P}_{\mathrm{i}}^{\prime \prime \prime}, & \text { otherwise }\end{cases}
\end{aligned}
$$

Thus the stego pixel block after hiding $t, t_{1}, t_{2}, t_{3}, t_{4}, t_{5}, t_{6}, t_{7}$, and $t_{8}$ bits of data in pixels $\mathrm{P}_{c}, \mathrm{P}_{1}, \mathrm{P}_{2}, \mathrm{P}_{3}, \mathrm{P}_{4}, \mathrm{P}_{5}, \mathrm{P}_{6}, \mathrm{P}_{7}$, and $\mathrm{P}_{8}$, respectively, is as shown in Figure 1(b).
The extraction algorithm operates on $3 \times 3$ pixel blocks as in embedding algorithm. The blocks are formed in a nonoverlapping manner. A typical stego block is represented in Figure 1(b). Retrieve the $t$ LSBs from $\mathrm{P}_{c}^{\prime}$. For $\mathrm{i}=1$ to 8 , find eight difference values as in

$$
\mathrm{d}_{\mathrm{i}}^{\prime}=\left|\mathrm{P}_{\mathrm{c}}^{\prime}-\mathrm{P}_{\mathrm{i}}^{\prime}\right|
$$

Each $\mathrm{d}_{\mathrm{i}}^{\prime}$ belongs to a range whose embedding capacity is $t_{\mathrm{i}}$ and lower bound is $\mathrm{L}_{\mathrm{i}}$. For $\mathrm{i}=1$ to 8 , find the decimal values of the embedded secret bit streams using

$$
\mathrm{S}_{\mathrm{i}}=\mathrm{d}_{\mathrm{i}}^{\prime}-\mathrm{L}_{\mathrm{i}}
$$

Now convert $S_{1}, S_{2}, S_{3}, S_{4}, S_{5}, S_{6}, S_{7}$, and $S_{8}$ into $t_{1}, t_{2}, t_{3}, t_{4}$, $t_{5}, t_{6}, t_{7}$, and $t_{8}$ binary bits, respectively.

The correctness of the extraction procedure is justified by the following mathematical discussions. That means how (8) is derived from (7) is described below.

As per (7), $\mathrm{d}_{\mathrm{i}}^{\prime}=\left|\mathrm{P}_{\mathrm{c}}^{\prime}-\mathrm{P}_{\mathrm{i}}^{\prime}\right|$.

From (6), $\mathrm{P}_{\mathrm{i}}^{\prime}$ is $\mathrm{P}_{\mathrm{i}}^{\prime \prime}$, if $\left|\mathrm{P}_{\mathrm{i}}-\mathrm{P}_{\mathrm{i}}^{\prime \prime}\right|<\left|\mathrm{P}_{\mathrm{i}}-\mathrm{P}_{\mathrm{i}}^{\prime \prime \prime}\right|$ and $0 \leq \mathrm{P}_{\mathrm{i}}^{\prime \prime} \leq$ 255. Otherwise $\mathrm{P}_{\mathrm{i}}^{\prime}$ is $\mathrm{P}_{\mathrm{i}}^{\prime \prime \prime}$. So, $\mathrm{d}_{\mathrm{i}}^{\prime}$ can be defined as in

$$
\begin{aligned}
& \mathrm{d}_{\mathrm{i}}^{\prime} \\
& = \begin{cases}\left|\mathrm{P}_{\mathrm{c}}^{\prime}-\mathrm{P}_{\mathrm{i}}^{\prime \prime}\right|, & \text { if }\left|\mathrm{P}_{\mathrm{i}}-\mathrm{P}_{\mathrm{i}}^{\prime \prime}\right|<\left|\mathrm{P}_{\mathrm{i}}-\mathrm{P}_{\mathrm{i}}^{\prime \prime \prime}\right| \text { and } 0 \leq \mathrm{P}_{\mathrm{i}}^{\prime \prime} \leq 255 \\
\left|\mathrm{P}_{\mathrm{c}}^{\prime}-\mathrm{P}_{\mathrm{i}}^{\prime \prime \prime}\right|, & \text { otherwise }\end{cases}
\end{aligned}
$$

From (4) and (5), $\mathrm{P}_{\mathrm{i}}^{\prime \prime}=\left(\mathrm{P}_{\mathrm{c}}^{\prime}-\mathrm{d}_{\mathrm{i}}^{\prime}\right)$ and $\mathrm{P}_{\mathrm{i}}^{\prime \prime \prime}=\left(\mathrm{P}_{\mathrm{c}}^{\prime}+\mathrm{d}_{\mathrm{i}}^{\prime}\right)$, respectively. Substituting these values of $\mathrm{P}_{\mathrm{i}}^{\prime \prime}$ and $\mathrm{P}_{\mathrm{i}}^{\prime \prime \prime}$ in (9), (10) is obtained.

$$
\mathrm{d}_{\mathrm{i}}^{\prime}= \begin{cases}\left|\mathrm{P}_{\mathrm{c}}^{\prime}-\left(\mathrm{P}_{\mathrm{c}}^{\prime}-\mathrm{d}_{\mathrm{i}}^{\prime}\right)\right|, & \text { if }\left|\mathrm{P}_{\mathrm{i}}-\mathrm{P}_{\mathrm{i}}^{\prime \prime}\right|<\left|\mathrm{P}_{\mathrm{i}}-\mathrm{P}_{\mathrm{i}}^{\prime \prime \prime}\right| \text { and } 0 \leq \mathrm{P}_{\mathrm{i}}^{\prime \prime} \leq 255 \\ \left|\mathrm{P}_{\mathrm{c}}^{\prime}-\left(\mathrm{P}_{\mathrm{c}}^{\prime}+\mathrm{d}_{\mathrm{i}}^{\prime}\right)\right|, & \text { otherwise }\end{cases}
$$

Equation (10) can be simplified as

$$
\mathrm{d}_{\mathrm{i}}^{\prime}= \begin{cases}\left|\mathrm{d}_{\mathrm{i}}^{\prime}\right|, & \text { if }\left|\mathrm{P}_{\mathrm{i}}-\mathrm{P}_{\mathrm{i}}^{\prime \prime}\right|<\left|\mathrm{P}_{\mathrm{i}}-\mathrm{P}_{\mathrm{i}}^{\prime \prime \prime}\right| \text { and } 0 \leq \mathrm{P}_{\mathrm{i}}^{\prime \prime} \leq 255 \\ \left|-\mathrm{d}_{\mathrm{i}}^{\prime}\right|, & \text { otherwise }\end{cases}
$$

From (3), $\mathrm{d}_{\mathrm{i}}^{\prime}=\mathrm{L}_{\mathrm{i}}+\mathrm{S}_{\mathrm{i}}$. Substituting $\mathrm{d}_{\mathrm{i}}^{\prime}$ on right hand side of (11), (12) is obtained.

$$
\begin{aligned}
& \mathrm{d}_{\mathrm{i}}^{\prime} \\
& = \begin{cases}\mathrm{L}_{\mathrm{i}}+\mathrm{S}_{\mathrm{i}}, & \text { if }\left|\mathrm{P}_{\mathrm{i}}-\mathrm{P}_{\mathrm{i}}^{\prime \prime}\right|<\left|\mathrm{P}_{\mathrm{i}}-\mathrm{P}_{\mathrm{i}}^{\prime \prime \prime}\right| \text { and } 0 \leq \mathrm{P}_{\mathrm{i}}^{\prime \prime} \leq 255 \\
\mathrm{~L}_{\mathrm{i}}+\mathrm{S}_{\mathrm{i}}, & \text { otherwise }\end{cases}
\end{aligned}
$$

From (12), it can be concluded that $\mathrm{d}_{\mathrm{i}}^{\prime}=\mathrm{L}_{\mathrm{i}}+\mathrm{S}_{\mathrm{i}}$ or $\mathrm{S}_{\mathrm{i}}=\mathrm{d}_{\mathrm{i}}^{\prime}-$ $\mathrm{L}_{\mathrm{i}}$. This is nothing but (8) used in extraction procedure. Thus correctness of (8) is justified.

\section{Examples for Embedding and Extraction}

Figure 2 represents an example of embedding for type 1 with $t=3$ of the proposed technique. It is self-explanatory. To understand this example it can be traversed from left to right and top to bottom.

Figure 3 represents an example of extraction for type 1 with $t=3$ of the proposed technique. It is self-explanatory. To understand this example it can be traversed from left to right and top to bottom.

\section{Results and Discussion}

The embedding and extraction algorithms are simulated in MATLAB. Standard RGB color images from SIPI image data base are used for testing. The R, G, and B components (each 8 bits) of a pixel are treated as a single unit. For eight sample images the results are discussed and averaged. Figure 4 shows the original images, Figure 5 shows the stego images of type 1, and Figure 6 shows the stego images of type 2. In each of these stego images seven lakhs $(700,000)$ bits of data is hidden. The evaluation parameters are (i) hiding capacity; (ii) bit rate (BPB); (iii) PSNR and quality index (Q). The hiding capacity is the total number of bits that an image can conceal. The bits 


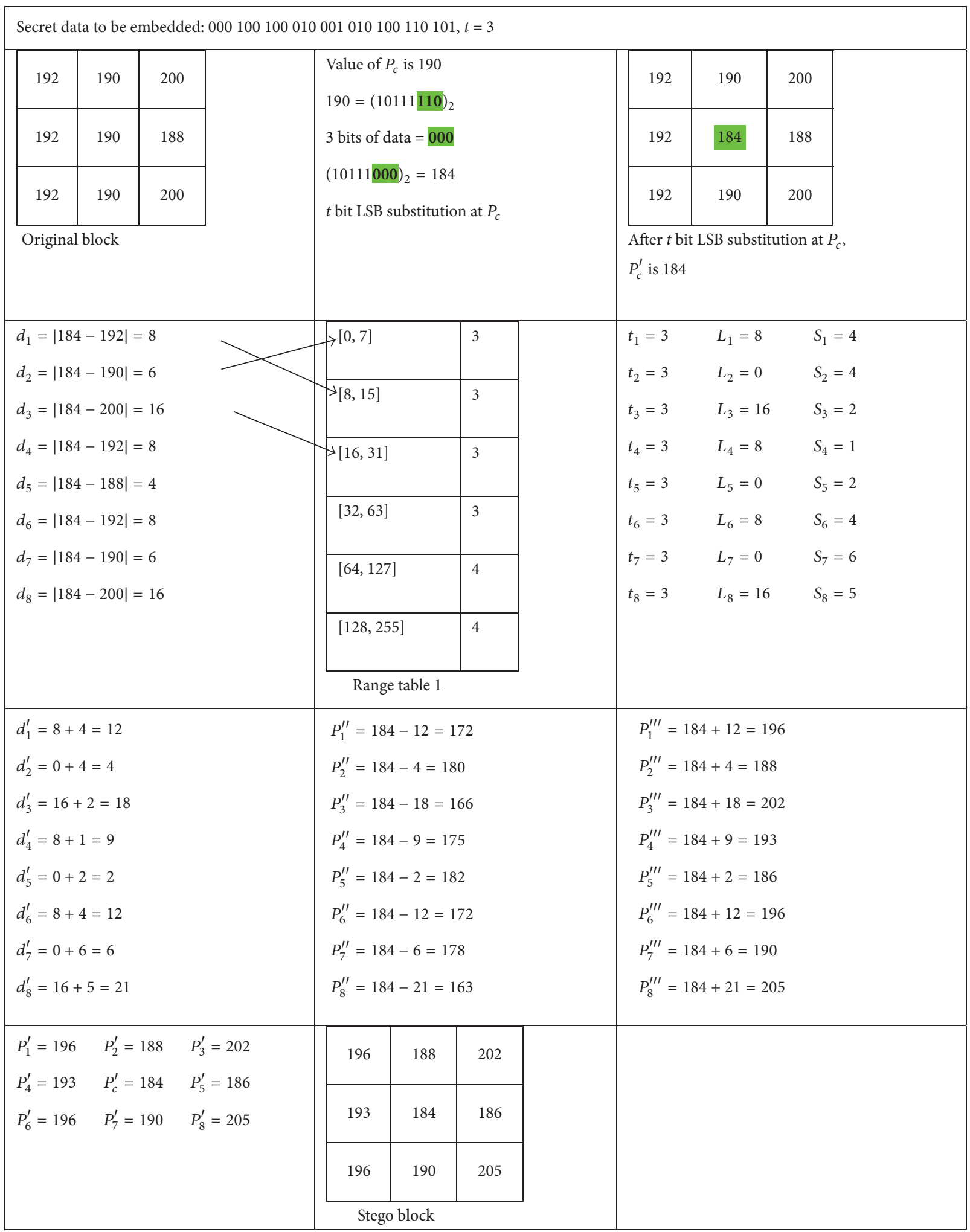

FIgURE 2: Example of embedding. 


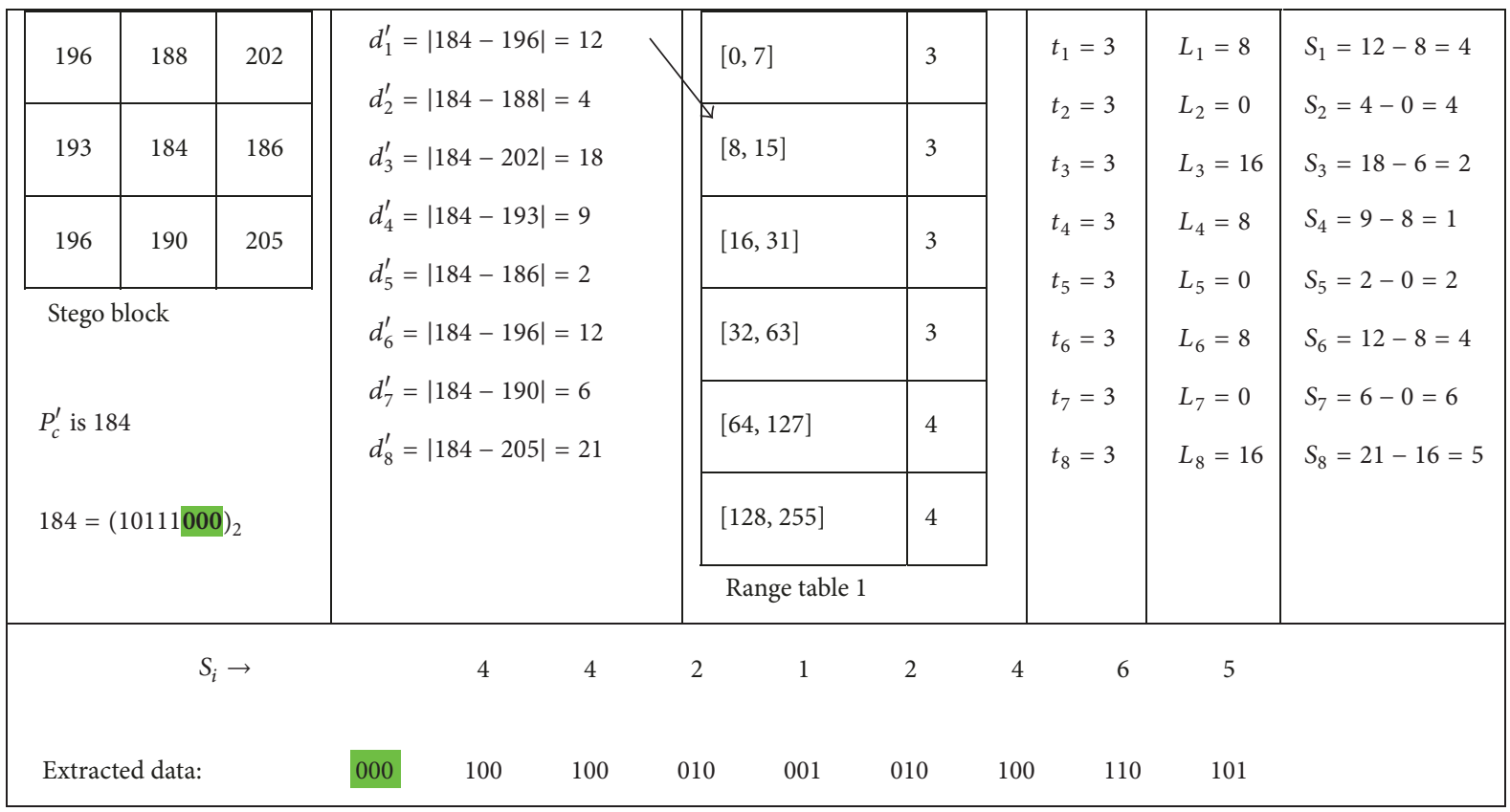

FIgURE 3: Example of extraction.

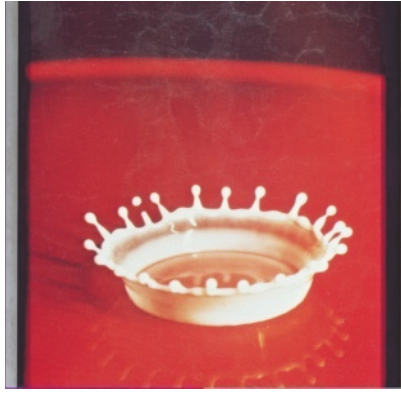

(a) Pot

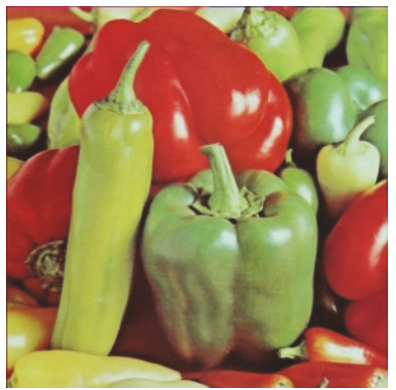

(e) Peppers

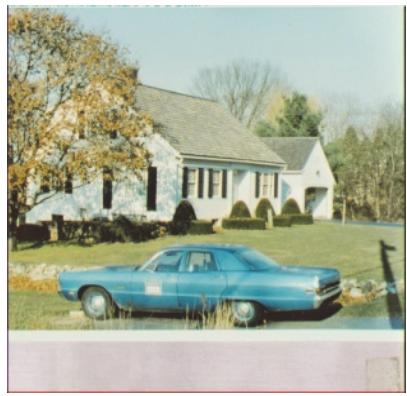

(b) House

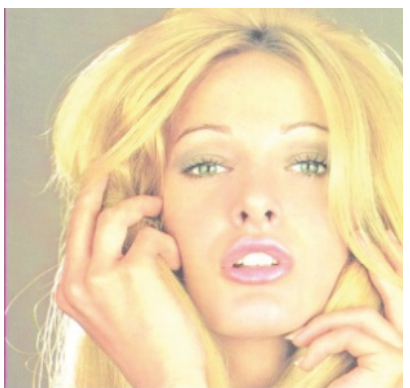

(f) Tiffany

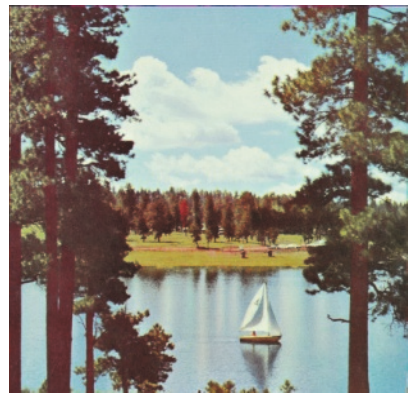

(c) Boat

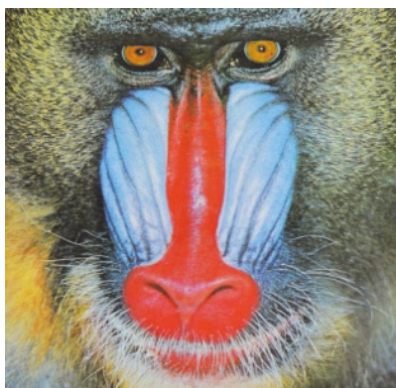

(g) Baboon

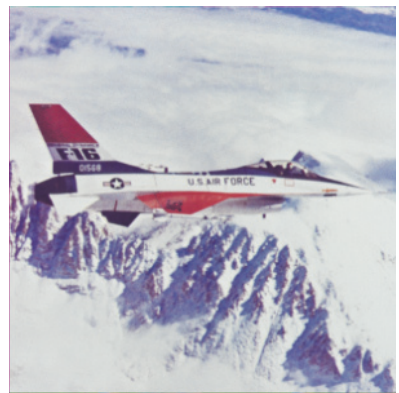

(d) Jet

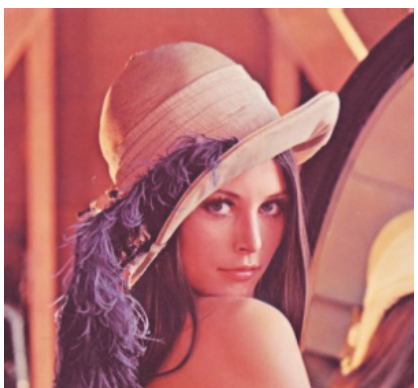

(h) Lena

FIGURE 4: Original images.

per byte (BPB) indicate the average hiding capacity per a byte of the original image. Equation (13) is used to calculate BPB.

$$
\mathrm{BPB}=\frac{\text { hiding capacity }}{\text { image size in bytes }}
$$

Distortion in stego image is measured in terms of PSNR. Equation (14) is used to calculate it.

$$
\mathrm{PSNR}=10 \times \log _{10} \frac{255 \times 255}{\mathrm{MSE}}
$$

where MSE denotes the mean square error and can be computed using

$$
\text { MSE }=\frac{1}{m \times n} \sum_{i=1}^{m} \sum_{j=1}^{n}\left(p_{i j}-q_{i j}\right)^{2}
$$

where $\mathrm{p}_{\mathrm{ij}}$ is a pixel of cover image and $\mathrm{q}_{\mathrm{ij}}$ is the corresponding stego pixel.

The quality index $(\mathrm{Q})$ is another parameter to measure the structural similarity between original image and stego image. 


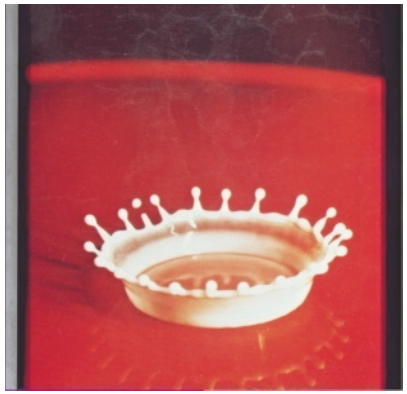

$\mathrm{PSNR}=41.15$

(a)

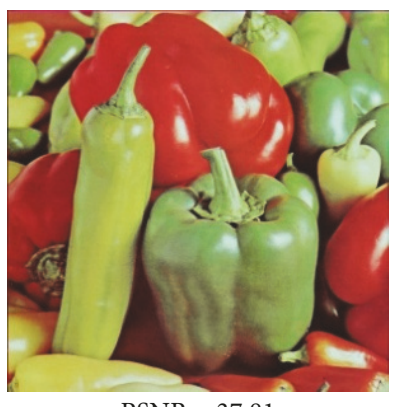

$\mathrm{PSNR}=37.81$

(e)

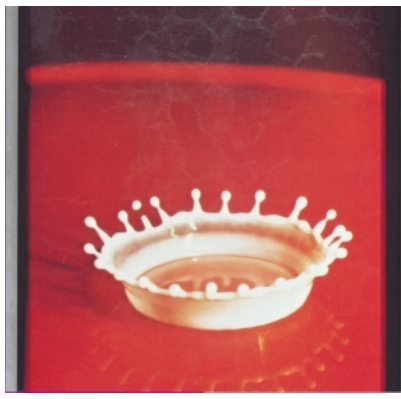

$\mathrm{PSNR}=37.11$

(a)

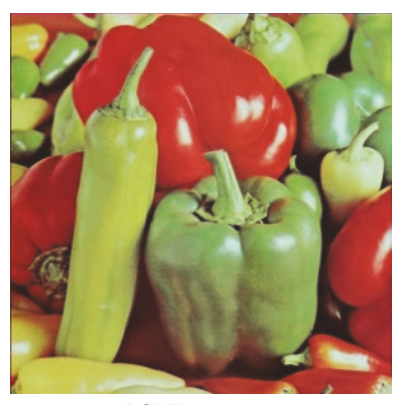

$\mathrm{PSNR}=34.69$

(e)

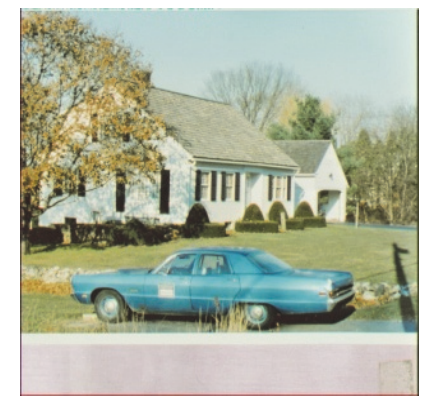

PSNR $=39.69$

(b)

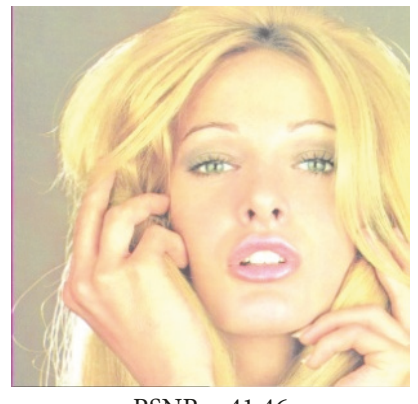

PSNR $=41.46$

(f)

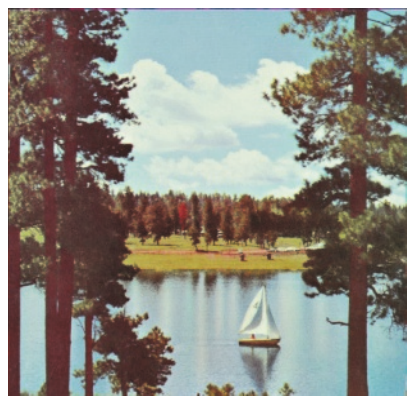

$\operatorname{PSNR}=37.25$

(c)

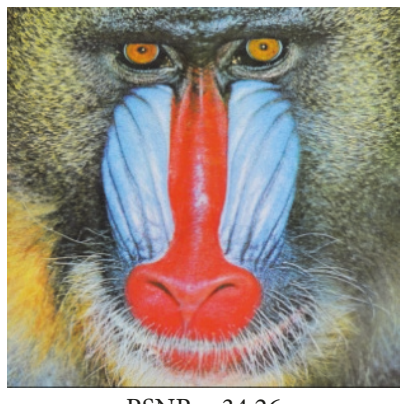

PSNR $=34.26$

(g)

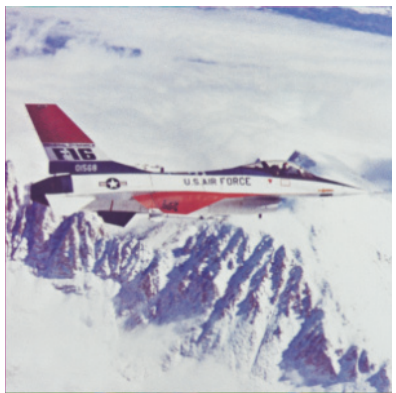

$\mathrm{PSNR}=42.21$

(d)

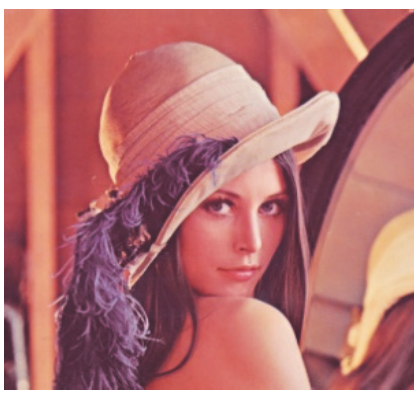

PSNR $=42.62$

(h)

FIGURE 5: Stego images of proposed type $1(\mathrm{t}=3$, range table 1).

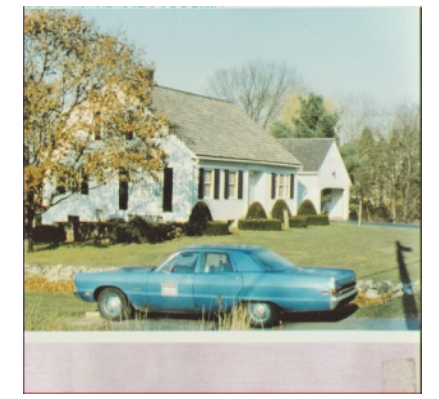

$\mathrm{PSNR}=38.39$

(b)

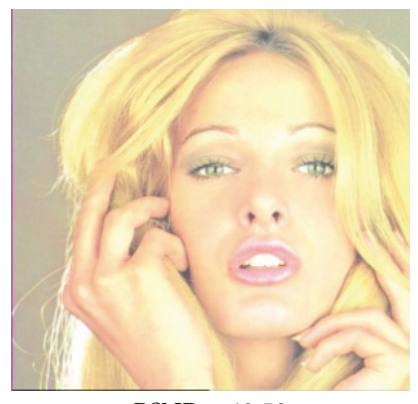

$\mathrm{PSNR}=40.53$

(f)

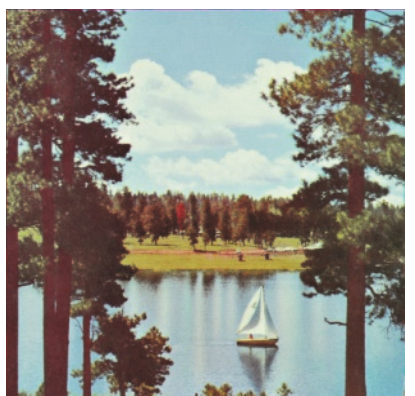

PSNR $=34.08$

(c)

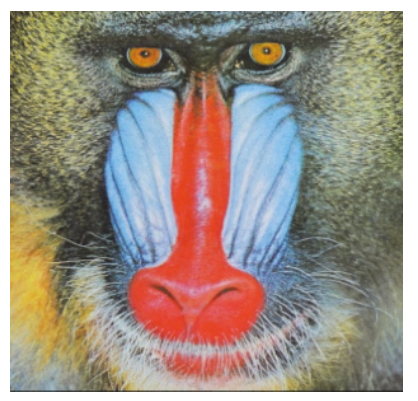

PSNR $=32.09$

(g)

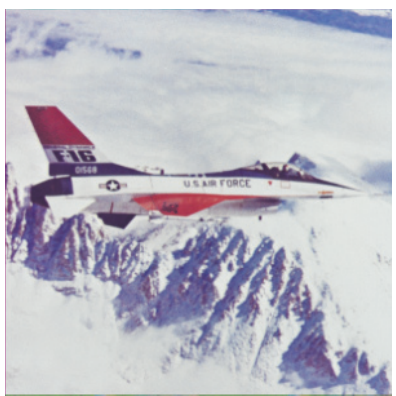

$\mathrm{PSNR}=40.38$

(d)

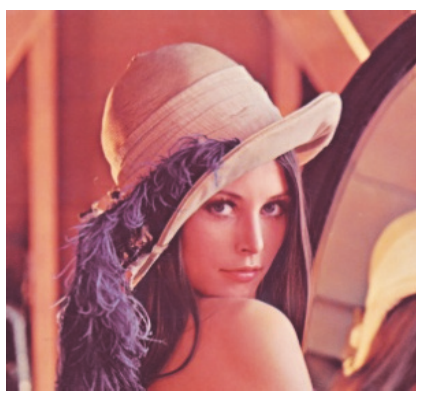

$\mathrm{PSNR}=40.48$

(h)

FIgURE 6: Stego images of proposed type $2(\mathrm{t}=4$, range table 2$)$. 
TABLE 3: Results of Pradhan et al.'s seven-way PVD technique [18].

\begin{tabular}{|c|c|c|c|c|c|c|c|c|}
\hline \multirow{2}{*}{ Images $512 \times 512 \times 3$} & \multicolumn{4}{|c|}{ Seven-way PVD [18] } & \multicolumn{4}{|c|}{ Seven-way+ one-way PVD [18] } \\
\hline & PSNR & Capacity & Q & $\mathrm{BPB}$ & PSNR & Capacity & Q & $\mathrm{BPB}$ \\
\hline Pot & 42.37 & 1795551 & 0.9996 & 2.28 & 42.40 & 1803635 & 0.9996 & 2.29 \\
\hline House & 38.97 & 1972223 & 0.9986 & 2.50 & 38.98 & 1977403 & 0.9986 & 2.51 \\
\hline Boat & 37.89 & 1972086 & 0.9988 & 2.50 & 37.91 & 1991005 & 0.9988 & 2.53 \\
\hline Jet & 42.09 & 1906254 & 0.9989 & 2.42 & 41.98 & 1909595 & 0.9989 & 2.42 \\
\hline Peppers & 40.42 & 1778072 & 0.9993 & 2.26 & 40.20 & 1806166 & 0.9992 & 2.29 \\
\hline Tiffany & 41.23 & 1400756 & 0.9986 & 1.78 & 41.30 & 1450799 & 0.9986 & 1.84 \\
\hline Baboon & 33.79 & 2226806 & 0.9957 & 2.83 & 33.77 & 2243218 & 0.9957 & 2.85 \\
\hline Lena & 41.73 & 1896662 & 0.9993 & 2.41 & 41.73 & 1901149 & 0.9993 & 2.41 \\
\hline Average & 39.81 & 1868551 & 0.9986 & 2.37 & 39.78 & 1885371 & 0.9985 & 2.39 \\
\hline
\end{tabular}

TABLE 4: Results of Khodaei and Faez's technique.

\begin{tabular}{|c|c|c|c|c|c|c|c|c|}
\hline \multirow{2}{*}{ Images $512 \times 512 \times 3$} & \multicolumn{4}{|c|}{ Khodaei and Faez, type $1[10]$} & \multicolumn{4}{|c|}{ Khodaei and Faez, type 2 [10] } \\
\hline & PSNR & Capacity & Q & $\mathrm{BPB}$ & PSNR & Capacity & Q & $\mathrm{BPB}$ \\
\hline Pot & 41.21 & 2366001 & 0.9995 & 3.00 & 37.83 & 2387494 & 0.9990 & 3.03 \\
\hline House & 39.16 & 2387183 & 0.9986 & 3.03 & 38.75 & 2470824 & 0.9985 & 3.14 \\
\hline Boat & 40.05 & 2391994 & 0.9993 & 3.04 & 37.49 & 2504613 & 0.9987 & 3.18 \\
\hline Jet & 40.89 & 2374048 & 0.9986 & 3.01 & 40.64 & 2418419 & 0.9985 & 3.07 \\
\hline Peppers & 39.32 & 2372858 & 0.9991 & 3.01 & 37.91 & 2435223 & 0.9987 & 3.09 \\
\hline Tiffany & 39.73 & 2372396 & 0.9980 & 3.01 & 40.25 & 2416944 & 0.9982 & 3.07 \\
\hline Baboon & 37.77 & 2443361 & 0.9982 & 3.10 & 34.49 & 2662080 & 0.9963 & 3.38 \\
\hline Lena & 42.78 & 2375248 & 0.9995 & 3.02 & 41.25 & 2434603 & 0.9993 & 3.09 \\
\hline Average & 40.11 & 2385386 & 0.9988 & 3.03 & 38.57 & 2466275 & 0.9984 & 3.13 \\
\hline
\end{tabular}

Equation (16) is used to compute it. The maximum value of Q can be 1 , if original image, $\mathrm{p}$, and stego image, $\mathrm{q}$, are the same.

$$
\mathrm{Q}=\frac{4 \sigma_{\mathrm{xy}} \overline{\mathrm{p}} \overline{\mathrm{q}}}{\left(\sigma_{\mathrm{x}}^{2}+\sigma_{\mathrm{y}}^{2}\right)\left[(\overline{\mathrm{p}})^{2}+(\overline{\mathrm{q}})^{2}\right]}
$$

where $\overline{\mathrm{p}}$ stands for the mean pixel value of the original image, $\bar{q}$ stands for the mean pixel value of the stego image, $\sigma_{x}^{2}$ stands for the standard deviation of pixel values of original image, $\sigma_{\mathrm{y}}^{2}$ stands for the standard deviation of pixel values of stego image, and $\sigma_{\mathrm{xy}}$ is the covariance between original image and stego image. Equations (17), (18), (19), (20), and (21) are used to calculate these values.

$$
\begin{aligned}
\overline{\mathrm{p}} & =\frac{1}{\mathrm{~m} \times \mathrm{n}} \sum_{\mathrm{i}=1}^{\mathrm{m}} \sum_{\mathrm{j}=1}^{\mathrm{n}} \mathrm{p}_{\mathrm{ij}} \\
\overline{\mathrm{q}} & =\frac{1}{\mathrm{~m} \times \mathrm{n}} \sum_{\mathrm{i}=1}^{\mathrm{m}} \sum_{\mathrm{j}=1}^{\mathrm{n}} \mathrm{q}_{\mathrm{ij}} \\
\sigma_{\mathrm{x}}^{2} & =\frac{1}{\mathrm{~m} \times \mathrm{n}-1} \sum_{\mathrm{i}=1}^{\mathrm{m}} \sum_{\mathrm{j}=1}^{\mathrm{n}}\left(\mathrm{p}_{\mathrm{ij}}-\overline{\mathrm{p}}\right)^{2} \\
\sigma_{\mathrm{y}}^{2} & =\frac{1}{\mathrm{~m} \times \mathrm{n}-1} \sum_{\mathrm{i}=1}^{\mathrm{m}} \sum_{\mathrm{j}=1}^{\mathrm{n}}\left(\mathrm{q}_{\mathrm{ij}}-\overline{\mathrm{q}}\right)^{2} \\
\sigma_{\mathrm{xy}} & =\frac{1}{\mathrm{~m} \times \mathrm{n}-1} \sum_{\mathrm{i}=1}^{\mathrm{m}} \sum_{\mathrm{j}=1}^{\mathrm{n}}\left(\mathrm{p}_{\mathrm{ij}}-\overline{\mathrm{p}}\right)\left(\mathrm{q}_{\mathrm{ij}}-\overline{\mathrm{q}}\right)
\end{aligned}
$$

Table 3 notes the results of seven-way PVD [18] which is an extension of $\mathrm{Wu}$ and Tsai's [1] technique. Table 4 notes the results of Khodaei and Faez's technique [10] and Table 5 notes the results of the proposed technique. The PSNR and capacity of the proposed technique (both type 1 and type 2) are better than seven-way PVD. The bit rate and Q are also better. Although as compared to Khodaei and Faez's technique the PSNR is not improved, but the hiding capacity is improved. The major advantage over Khodaei and Faez's technique is that the proposed technique is resistant to $\mathrm{PDH}$ analysis, but Khodaei and Faez's technique is detectable by $\mathrm{PDH}$ analysis. This is made possible by exploiting the edges in eight directions.

Now let us observe the results of proposed technique and compare type 1 and type 2 . We can observe that the capacity is higher in type 2 as compared to type 1 . This is because of the 4 LSBs substitution in type 2 at the central pixel; i.e., the $t$ value is 4 . On the other hand the PSNR of type 1 is better than that of type 2 .

Table 6 represents the comparison of the proposed technique with the adaptive PVD technique in [26] and hybrid techniques in $[27,28]$. The comparison parameters are average PSNR and average hiding capacity values. The two variants of adaptive PVD technique possess lesser hiding capacity as compared to the proposed eight-directional PVD. As the hiding capacity of adaptive PVD [26] is very little, so PSNR is larger. The hybrid technique proposed in [27] is a combination of PVD, LSB and EMD. The hiding capacity of proposed technique is greater than all the four variants of the hybrid technique proposed in [27]. The technique in [28] uses PVD with modified LSB (MLSB) substitution. The results of this technique (type 1) are as good as the results of 
TABLE 5: Results of proposed eight-directional PVD technique.

\begin{tabular}{|c|c|c|c|c|c|c|c|c|}
\hline \multirow{2}{*}{ Images $512 \times 512 \times 3$} & \multicolumn{4}{|c|}{ Proposed, type $1(\mathrm{t}=3$, Range Table 1$)$} & \multicolumn{4}{|c|}{ Proposed, type $2(\mathrm{t}=4$, Range Table 2$)$} \\
\hline & PSNR & Capacity & Q & $\mathrm{BPB}$ & PSNR & Capacity & Q & $\mathrm{BPB}$ \\
\hline Pot & 41.15 & 2354240 & 0.9996 & 2.99 & 37.11 & 2475977 & 0.9988 & 3.15 \\
\hline House & 39.69 & 2358575 & 0.9988 & 3.00 & 38.39 & 2625804 & 0.9984 & 3.34 \\
\hline Boat & 37.25 & 2364685 & 0.9987 & 3.01 & 34.08 & 2659795 & 0.9973 & 3.38 \\
\hline Jet & 42.21 & 2356828 & 0.9989 & 3.00 & 40.38 & 2538801 & 0.9985 & 3.23 \\
\hline Peppers & 37.81 & 2356645 & 0.9988 & 3.00 & 34.69 & 2544392 & 0.9975 & 3.24 \\
\hline Tiffany & 41.46 & 2353505 & 0.9987 & 2.99 & 40.53 & 2511139 & 0.9984 & 3.19 \\
\hline Baboon & 34.26 & 2392573 & 0.9961 & 3.04 & 32.09 & 2939376 & 0.9937 & 3.74 \\
\hline Lena & 42.62 & 2353892 & 0.9995 & 2.99 & 40.48 & 2533551 & 0.9992 & 3.22 \\
\hline Average & 39.55 & 2361368 & 0.9986 & 3.00 & 37.22 & 2603604 & 0.9977 & 3.31 \\
\hline
\end{tabular}

TABLE 6: Comparison of the proposed technique with techniques in [26-28].

\begin{tabular}{|c|c|c|c|}
\hline Technique & PSNR & Capacity & Amount of hidden data in stego image to compute PSNR \\
\hline $2 \times 3$ adaptive $\mathrm{PVD}[26]$ & 50.93 & 1445645 & \multirow{2}{*}{ One lakh and forty thousand $(140,000)$ bits } \\
\hline $3 \times 2$ adaptive PVD [26] & 50.93 & 1435623 & \\
\hline 3 PVD +3 LSB +EMD, type 1 [27] & 41.07 & 1686041 & \multirow{4}{*}{ Seven lakhs $(700,000)$ bits } \\
\hline 3 PVD +3 LSB +EMD, type 2 [27] & 38.95 & 1798834 & \\
\hline 7 PVD +3 LSB +EMD, type 1 [27] & 40.28 & 1710888 & \\
\hline 7 PVD +3 LSB +EMD, type 2 [27] & 37.26 & 1823282 & \\
\hline Proposed eight-directional PVD, type 1 & 39.55 & 2361368 & \multirow{2}{*}{ Seven lakhs $(700,000)$ bits } \\
\hline Proposed eight-directional PVD, type 2 & 37.22 & 2603604 & \\
\hline Five-directional PVD+MLSB, type 1 [28] & 37.62 & 2399853 & \multirow{4}{*}{ Eight lakhs and forty thousand $(840,000)$ bits } \\
\hline Five-directional PVD+MLSB, type 2 [28] & 36.23 & 2514038 & \\
\hline Eight-directional PVD+MLSB, type 1 [28] & 37.49 & 2394086 & \\
\hline Eight-directional PVD+MLSB, type 2 [28] & 35.60 & 2603604 & \\
\hline
\end{tabular}

the proposed technique (type 1). Similarly, the results of this technique (type 2) are as good as the results of the proposed technique (type 2).

\section{Security Analysis}

The LSB substitution techniques suffer from RS analysis and PVD techniques suffer from $\mathrm{PDH}$ analysis. The proposed technique uses the concepts like modified LSB substitution and PVD, so it must be analyzed by both RS analysis and PDH analysis.

The PDH analysis is performed by calculating the difference value between every pair of pixels. A pair comprises two consecutive pixels. This difference values will be from -255 to +255 including 0 . The frequency of each of these difference values is counted. A graph is plotted, with the pixel difference value on $\mathrm{X}$-axis and frequency on Y-axis. The curve obtained is called the PDH. The PDH of original image will be a smooth curve. If the PDH of stego image is also a smooth curve then steganography is not detected. If the $\mathrm{PDH}$ of stego image shows step effects, then steganography is identified.

Figure 7 is the PDH analysis of type 1 and Figure 8 is the PDH analysis of type 2 of the proposed technique. The analysis is carried over all the eight test images. For each image the $\mathrm{PDH}$ of the original image is represented by solid line and the PDH of the stego image is represented by dotted line. The solid line curves will be obviously free of step effects as they are of the original images. The dotted line curves in all the sixteen cases do not show any step effects. This justifies that the proposed technique is resistant to $\mathrm{PDH}$ analysis.

The RS analysis is based on statistical measures. It is done in the following manner. Define a function $\mathrm{F}_{1}: 2 \mathrm{n} \longleftrightarrow 2 \mathrm{n}+1$. It defines two transformations, (i) from value $2 \mathrm{n}$ to value $2 n+1$ and (ii) from value $2 n+1$ to value $2 n$. Similarly, define another function $\mathrm{F}_{-1}: 2 \mathrm{n} \longleftrightarrow 2 \mathrm{n}-1$. It defines other two transformations, (i) from value $2 n$ to value $2 n-1$ and (ii) from value $2 n-1$ to value $2 n$. The image, say $M$, is divided into a number of equal size blocks. Suppose such a block is $G$ whose pixels are $X_{1}, X_{2}, X_{3}, \ldots, X_{n}$. Then use the function $\mathrm{f}\left(\mathrm{X}_{1}, \mathrm{X}_{2}, \mathrm{X}_{3}, \ldots, \mathrm{X}_{\mathrm{n}}\right)=\sum_{\mathrm{i}=1}^{\mathrm{n}-1}\left|\mathrm{X}_{\mathrm{i}+1}-\mathrm{X}_{\mathrm{i}}\right|$ to measure the smoothness of $G$. Then apply $F_{1}$ to all the blocks of $M$ and define the two parameters $\mathrm{R}_{\mathrm{m}}$ and $\mathrm{S}_{\mathrm{m}}$ as in (22) and (23). Similarly, apply $\mathrm{F}_{-1}$ to all the blocks of $\mathrm{M}$ and define the two parameters $\mathrm{R}_{-\mathrm{m}}$ and $\mathrm{S}_{-\mathrm{m}}$ as in (24) and (25).

$\mathrm{R}_{\mathrm{m}}$

$=\frac{\text { No of blocks satisfying the condition } f\left(F_{1}(G)\right)>f(G)}{\text { Total number of blocks }}$

$\mathrm{S}_{\mathrm{m}}$

$=\frac{\text { No of blocks satisfying the condition } f\left(F_{1}(G)\right)<f(G)}{\text { Total number of blocks }}$

$\mathrm{R}_{-\mathrm{m}}$

$=\underline{\text { No of blocks satisfying the condition } f\left(F_{-1}(G)\right)>f(G)}$ 

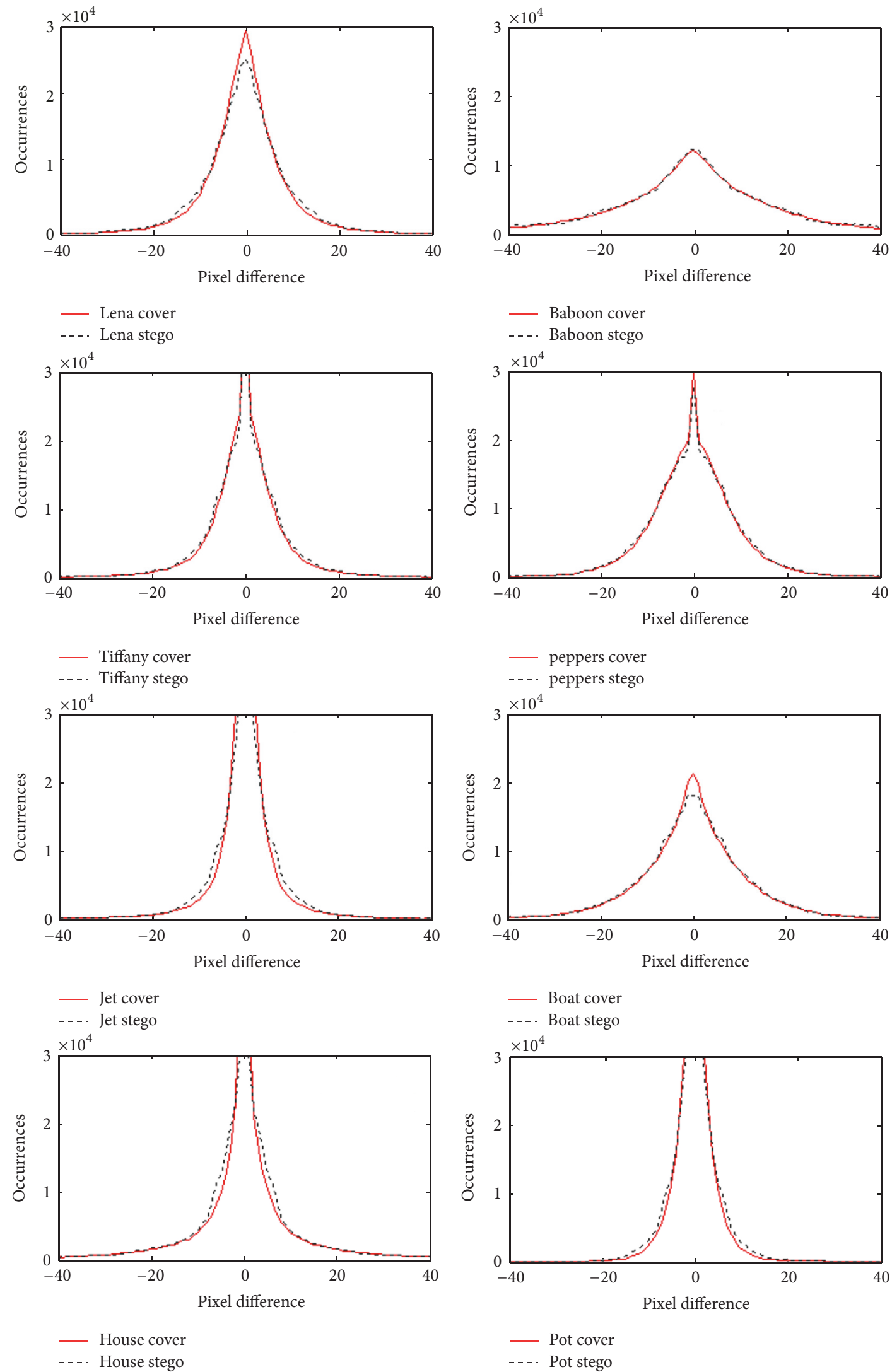

FIGURE 7: PDH analysis for type 1 of the proposed technique. 

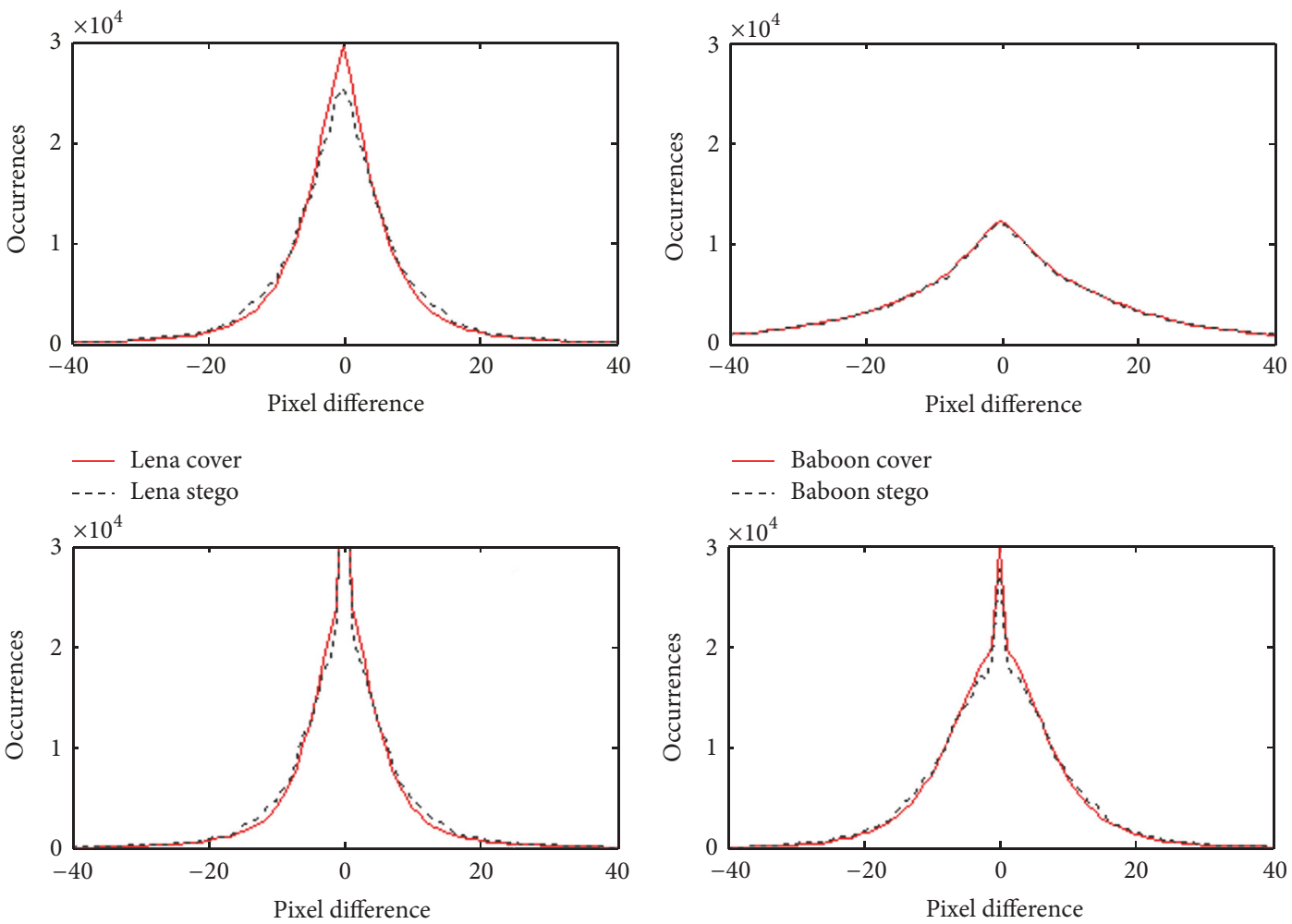

_. Baboon cover

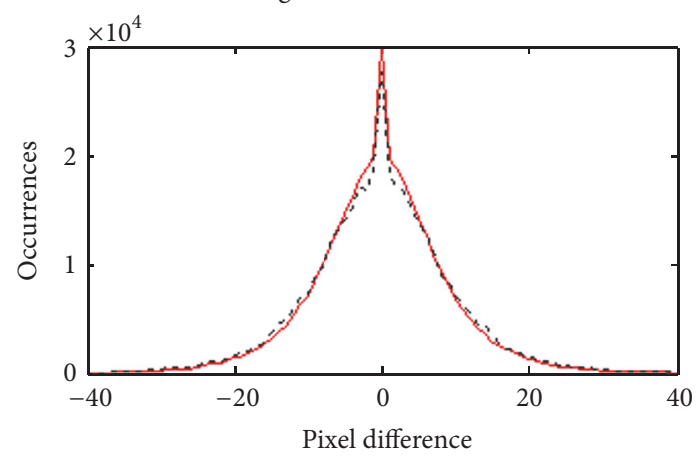

_- Tiffany cover

-... Tiffany stego

- peppers cover

- - - . peppers stego
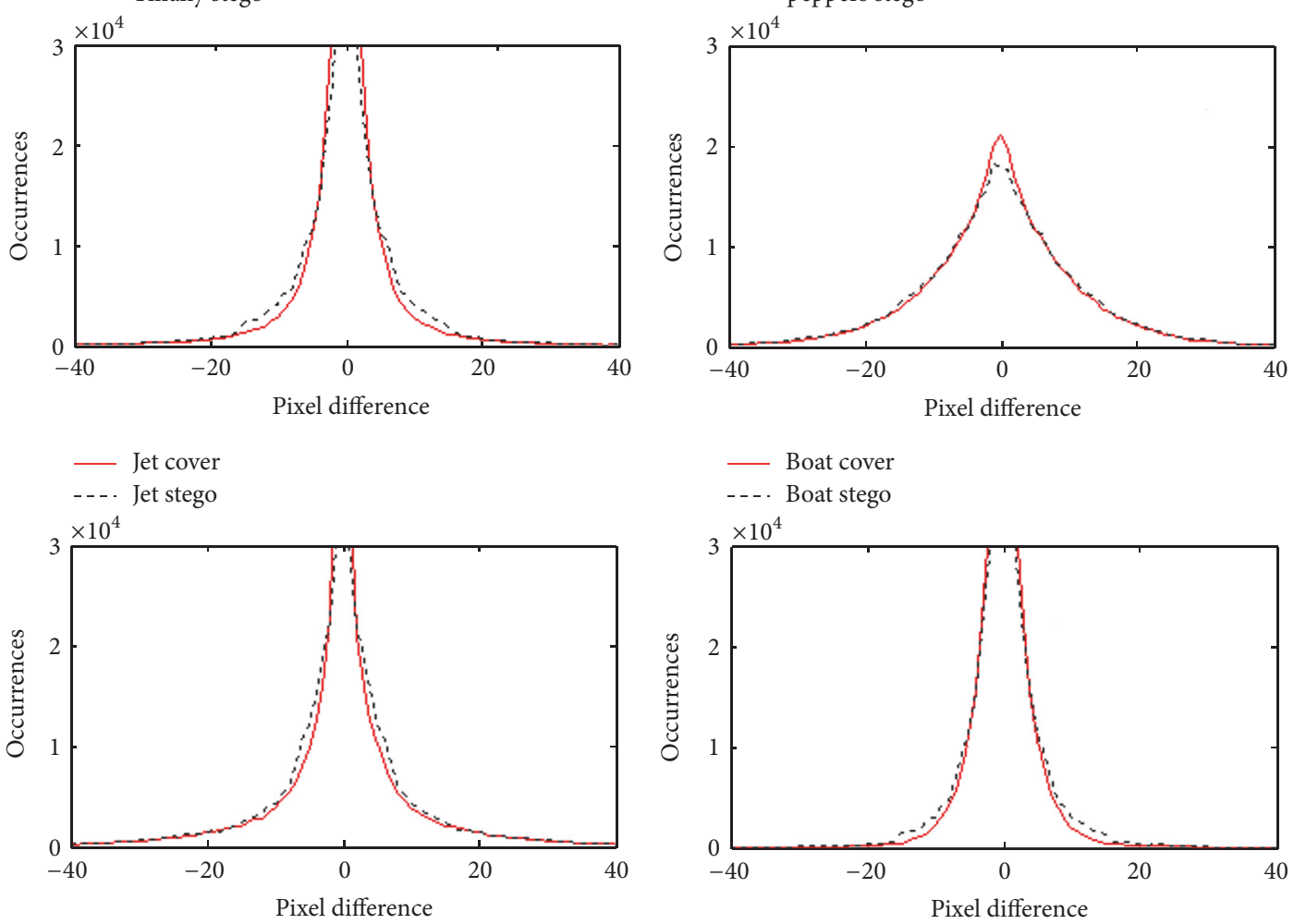

_. House cover

— Pot cover

-... Pot stego

FIGURE 8: PDH analysis for type 2 of the proposed technique. 


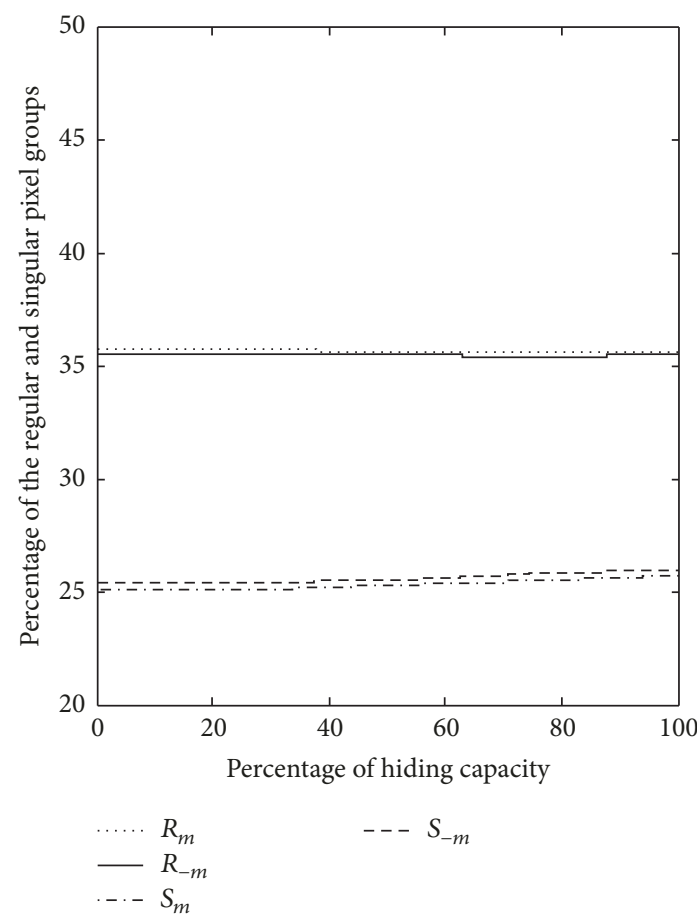

(a) Type 1, Lena

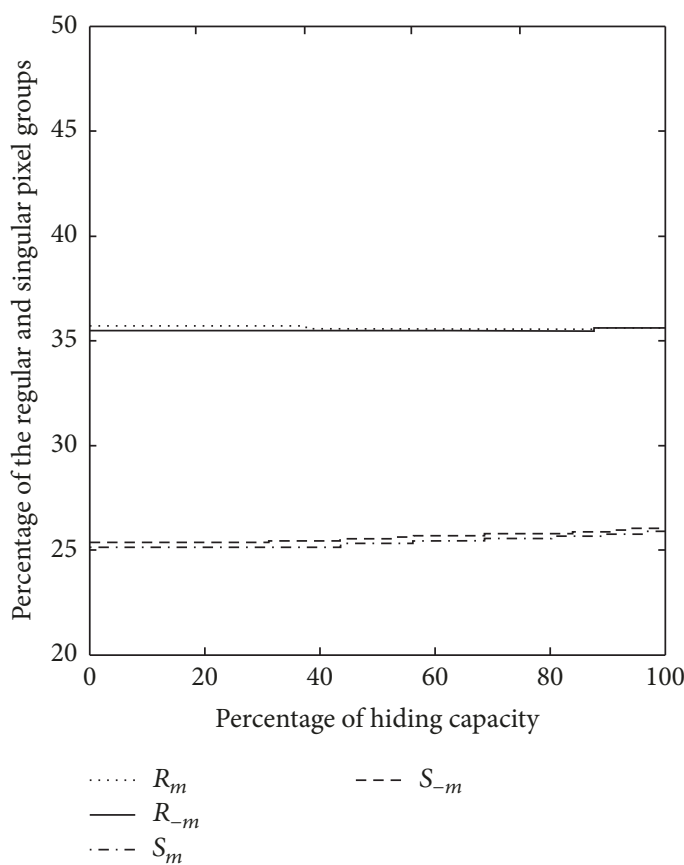

(c) Type 2, Lena

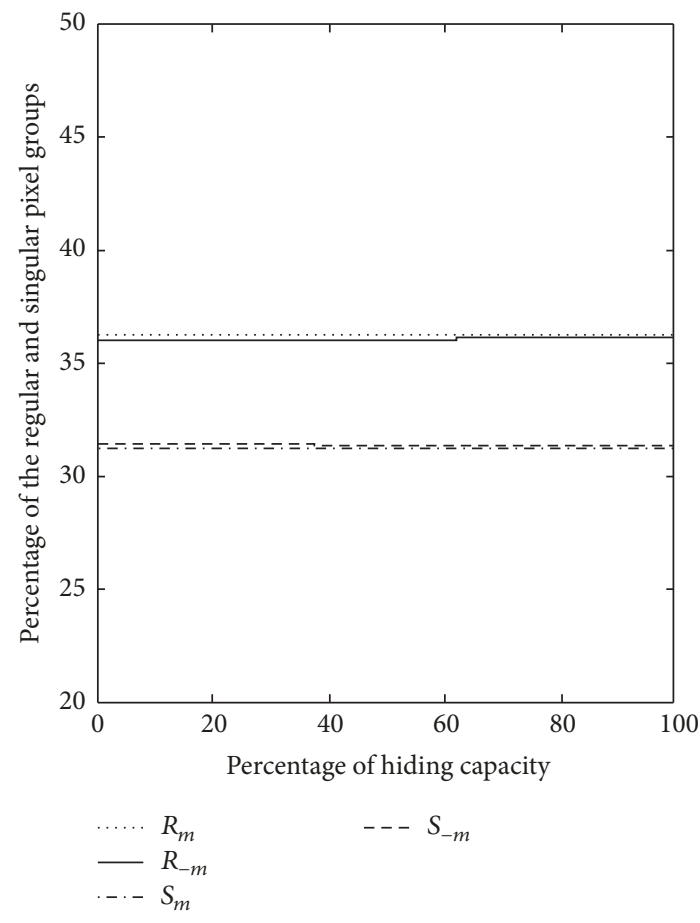

(b) Type 1, Baboon

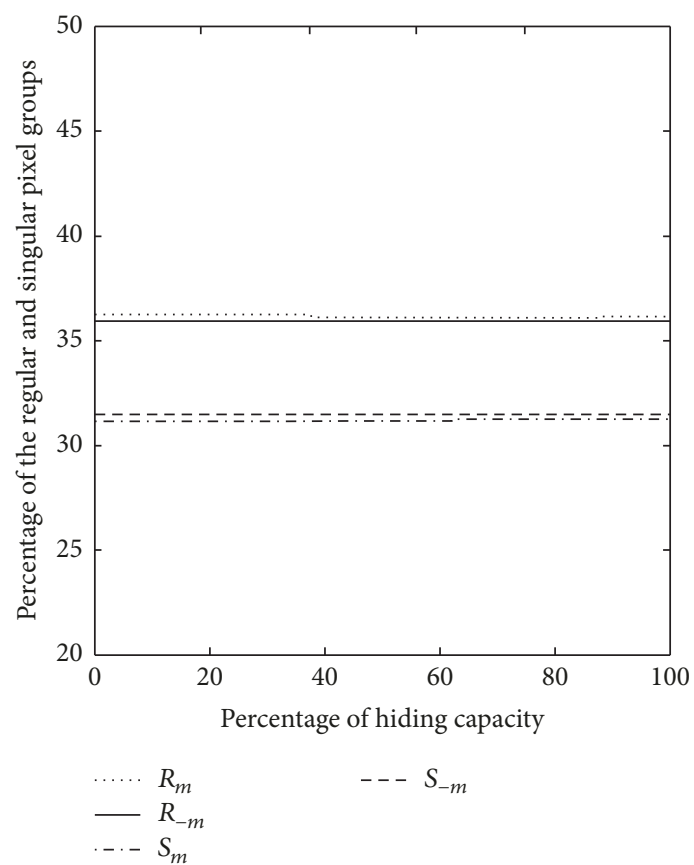

(d) Type 2, Baboon

FIGURE 9: RS analysis for type 1 and type 2 of the proposed technique.

$$
\begin{aligned}
& S_{-m} \\
& =\frac{\text { No of blocks satisfying the condition } f\left(F_{-1}(G)\right)<f(G)}{\text { Total number of blocks }}
\end{aligned}
$$

$\mathrm{RS}$ analysis is performed by using these four parameters. If the condition $\mathrm{R}_{m} \approx \mathrm{R}_{-m}>\mathrm{S}_{\mathrm{m}} \approx \mathrm{S}_{-\mathrm{m}}$ is true, then RS analysis fails to detect the steganography technique. But if the condition $\mathrm{R}_{-m}-\mathrm{S}_{-\mathrm{m}}>\mathrm{R}_{\mathrm{m}}-\mathrm{S}_{\mathrm{m}}$ is true, then the RS analysis succeeds in detecting the steganography technique.

Figure 9 represents RS analysis for the proposed technique. Figures 9(a) and 9(b) stand for RS analysis over Lena and Baboon images, respectively, of type 1. Similarly, Figures 9(c) and 9(d) stand for RS analysis over Lena and Baboon images, respectively, of type 2. In all the four cases the 
condition $\mathrm{R}_{m} \approx \mathrm{R}_{-m}>\mathrm{S}_{\mathrm{m}} \approx \mathrm{S}_{-\mathrm{m}}$ is true, so we can conclude that RS analysis could not detect the proposed technique. Lena image has more smooth regions and Baboon image has more edge regions; all the remaining six images are in between these two in terms of smoothness. So it is sufficient to draw a conclusion based on these two images.

\section{Conclusion}

The traditional PVD steganography techniques follow a static range table. Due to this some undesired steps are introduced in pixel difference histograms of the stego images. This step effect could be avoided by exploiting edges in eight different directions. This paper proposes a steganography technique using a judicious combination of LSB substitution and eightdirectional PVD. The LSB substitution is performed only in one pixel out of nine pixels in a block, so RS analysis cannot detect it. By using the edges in multiple directions the $\mathrm{PDH}$ analysis cannot detect it. There exist two types of the proposed technique, with regard to two different quantization tables. The type 1 provides higher PSNR and the type 2 provides higher hiding capacity. This proposed technique performs better in terms of hiding capacity and PSNR over other competing PVD techniques.

\section{Conflicts of Interest}

The author declares that there are no conflicts of interest.

\section{References}

[1] D.-C. Wu and W.-H. Tsai, "A steganographic method for images by pixel-value differencing," Pattern Recognition Letters, vol. 24, no. 9-10, pp. 1613-1626, 2003.

[2] K. C. Chang, C. P. Chang, P. S. Huang, and T. M. Tu, "A novel image steganographic method using tri-way pixel-value differencing," Journal of Multimedia, vol. 3, no. 2, pp. 37-44, 2008.

[3] Y.-P. Lee, J.-C. Lee, W.-K. Chen, K.-C. Chang, I.-J. Su, and C.P. Chang, "High-payload image hiding with quality recovery using tri-way pixel-value differencing," Information Sciences, vol. 191, pp. 214-225, 2012.

[4] C.-C. Chang and H.-W. Tseng, "A steganographic method for digital images using side match," Pattern Recognition Letters, vol. 25, no. 12, pp. 1431-1437, 2004.

[5] C.-H. Yang, C.-Y. Weng, H.-K. Tso, and S.-J. Wang, "A data hiding scheme using the varieties of pixel-value differencing in multimedia images," The Journal of Systems and Software, vol. 84, no. 4, pp. 669-678, 2011.

[6] W. Hong, T.-S. Chen, and C.-W. Luo, "Data embedding using pixel value differencing and diamond encoding with multiplebase notational system," The Journal of Systems and Software, vol. 85, no. 5, pp. 1166-1175, 2012.

[7] H. C. Wu, N. I. Wu, C. S. Tsai, and M.-S. Hwang, "Image steganographic scheme based on pixel-value differencing and LSB replacement methods," IEE Proceedings-Vision, Image and Signal Processing, vol. 152, no. 5, pp. 611-615, 2005.

[8] C.-H. Yang, C.-Y. Weng, S.-J. Wang, and H.-M. Sun, "Varied PVD + LSB evading detection programs to spatial domain in data embedding systems," The Journal of Systems and Software, vol. 83, no. 10, pp. 1635-1643, 2010.

[9] J. Chen, "A PVD-based data hiding method with histogram preserving using pixel pair matching," Signal Processing: Image Communication, vol. 29, no. 3, pp. 375-384, 2014.

[10] M. Khodaei and K. Faez, "New adaptive steganographic method using least-significant-bit substitution and pixel-value differencing," IET Image Processing, vol. 6, no. 6, pp. 677-686, 2012.

[11] G. Swain, "A steganographic method combining LSB substitution and PVD in a block," Procedia Computer Science, vol. 85, pp. 39-44, 2016.

[12] X. Liao, Q. Wen, and J. Zhang, "A steganographic method for digital images with four-pixel differencing and modified LSB substitution," Journal of Visual Communication and Image Representation, vol. 22, no. 1, pp. 1-8, 2011.

[13] G. Swain, "Digital image steganography using nine-pixel differencing and modified LSB substitution," Indian Journal of Science and Technology, vol. 7, no. 9, pp. 1444-1450, 2014, http://www.indjst.org/index.php/indjst/article/.

[14] W. Luo, F. Huang, and J. Huang, "A more secure steganography based on adaptive pixel-value differencing scheme," Multimedia Tools and Applications, vol. 52, no. 2-3, pp. 407-430, 2011.

[15] G. Swain, "Adaptive pixel value differencing steganography using both vertical and horizontal edges," Multimedia Tools and Applications, vol. 75, no. 21, pp. 13541-13556, 2016.

[16] S. Chakraborty, A. S. Jalal, and C. Bhatnagar, "LSB based non blind predictive edge adaptive image steganography," Multimedia Tools and Applications, vol. 76, no. 6, pp. 7973-7987, 2017.

[17] C. Balasubramanian, S. Selvakumar, and S. Geetha, "High payload image steganography with reduced distortion using octonary pixel pairing scheme," Multimedia Tools and Applications, vol. 73, no. 3, pp. 2223-2245, 2014.

[18] A. Pradhan, K. R. Sekhar, and G. Swain, "Digital image steganography based on seven way pixel value differencing," Indian Journal of Science and Technology, vol. 9, no. 37, pp. 1-11, 2016.

[19] K. A. Darabkh, A. K. Al-Dhamari, and I. F. Jafar, "A new steganographic algorithm based on multi directional PVD and modified LSB," Information Technology and Control, vol. 46, no. 1, pp. 16-36, 2017.

[20] A. K. Gulve and M. S. Joshi, "A high capacity secured image steganography method with five pixel pair differencing and LSB substitution," International Journal of Image, Graphics and Signal Processing, vol. 7, no. 5, pp. 66-74, 2015.

[21] X. Zhang and S. Wang, "Efficient steganographic embedding by exploiting modification direction," IEEE Communications Letters, vol. 10, no. 11, pp. 781-783, 2006.

[22] C. Kim, "Data hiding by an improved exploiting modification direction," Multimedia Tools and Applications, vol. 69, no. 3, pp. 569-584, 2014

[23] S. Y. Shen and L. H. Huang, "A data hiding scheme using pixel value differencing and improving exploiting modification directions," Computers \& Security, vol. 48, pp. 131-141, 2015.

[24] T. D. Nguyen, S. Arch-Int, and N. Arch-Int, "An adaptive multi bit-plane image steganography using block data-hiding," Multimedia Tools and Applications, vol. 75, no. 14, pp. 8319-8345, 2016.

[25] A. Soria-Lorente and S. Berres, "A secure steganographic algorithm based on frequency domain for the transmission of hidden information," Security and Communication Networks, vol. 2017, Article ID 5397028, 14 pages, 2017. 
[26] A. Pradhan, K. R. Sekhar, and G. Swain, "Adaptive PVD steganography using horizontal, vertical, and diagonal edges in six-pixel blocks," Security and Communication Networks, vol. 2017, Article ID 1924618, 13 pages, 2017.

[27] A. Pradhan, K. R. ekhar, and G. Swain, "Digital image steganography using LSB substitution, PVD, and EMD," Mathematical Problems in Engineering, 2018.

[28] G. Swain, "High capacity image steganography using modified LSB substitution and PVD against pixel difference histogram analysis," Security and Communication Networks, 2018. 


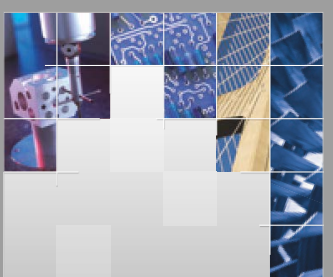

\section{Enfincering}
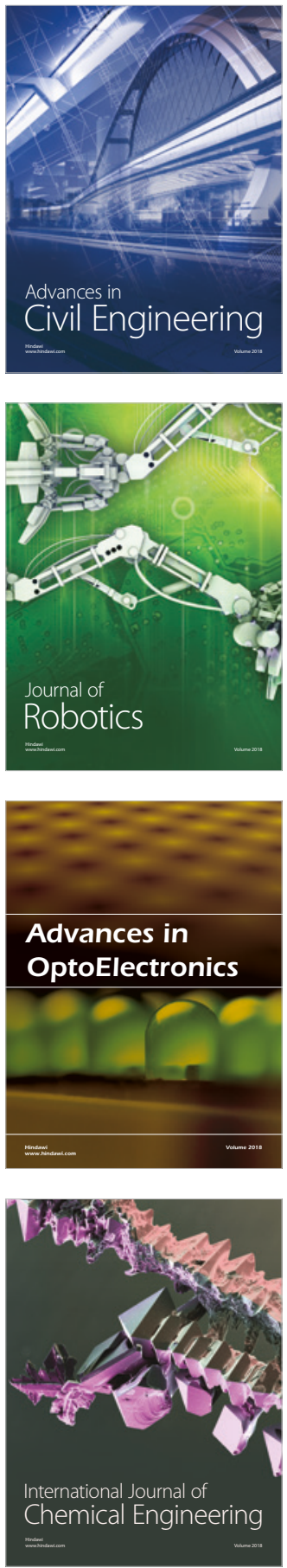

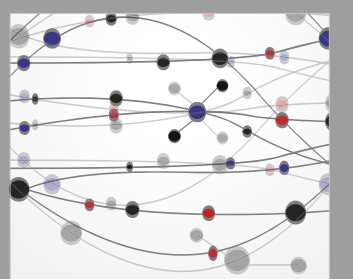

\section{Rotating \\ Machinery}

The Scientific World Journal

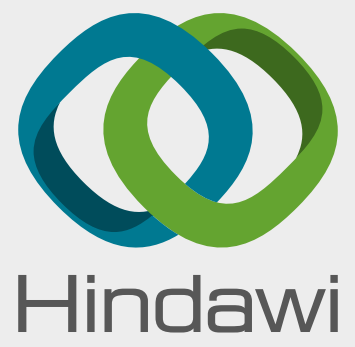

Submit your manuscripts at

www.hindawi.com
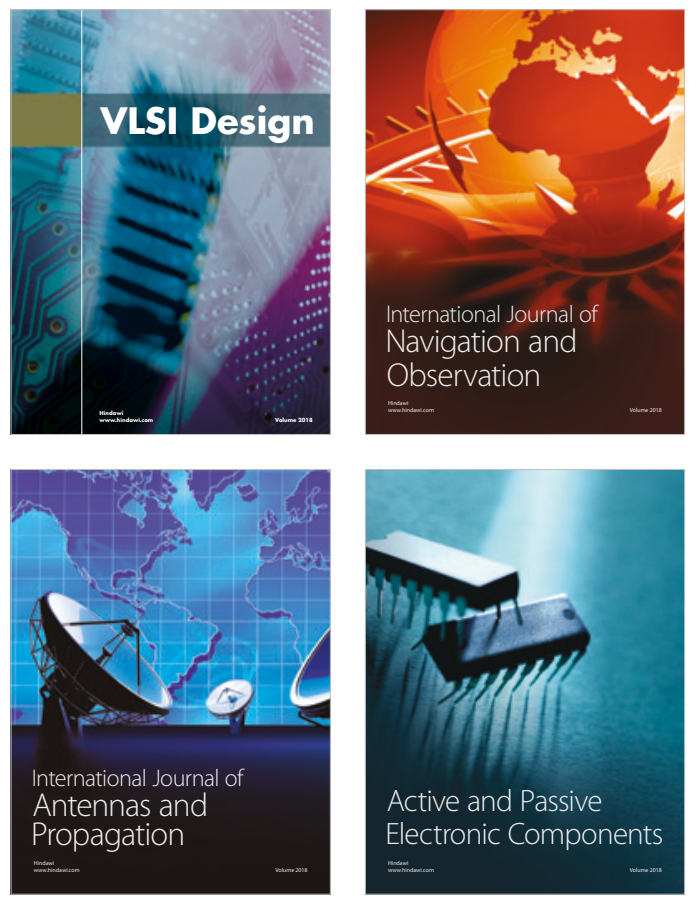
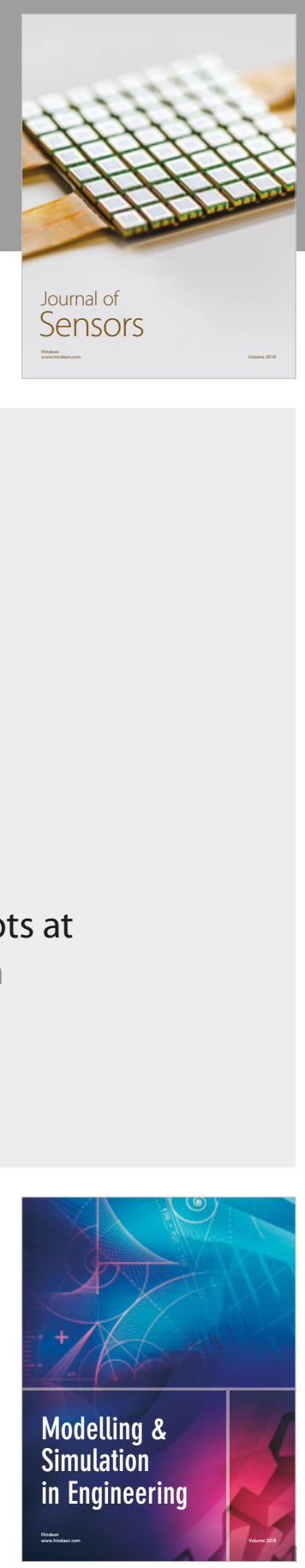

\section{Advances \\ Multimedia}
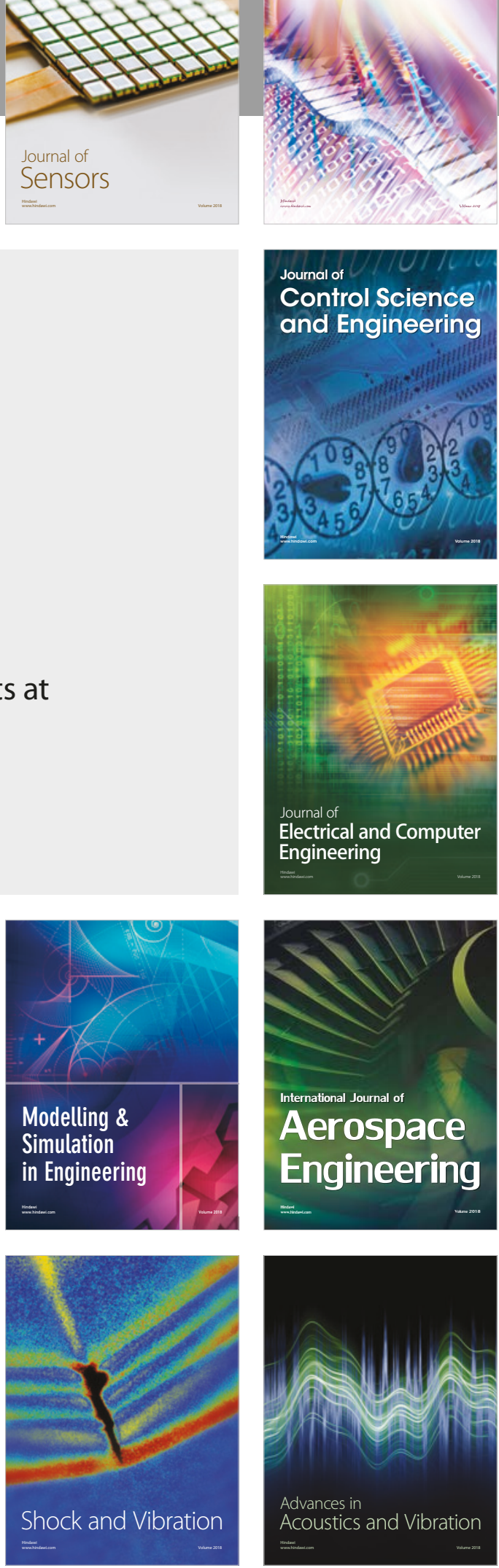